\title{
Management of Transverse Testicular Ectopia with Persistent Mullerian Duct Syndrome
}

\author{
Dabri Cansaran, ${ }^{1}$ () Serdar Moralioglu, ${ }^{1}$ ㄴ) Aysenur Celayir, ${ }^{1}$ \\ D Oktav Bosnali, ${ }^{1}$ (D) Rahime Gul Yesiltepe Mutlu² \\ ${ }^{1}$ Department of Pediatric Surgery, University of Health Sciences, Istanbul Zeynep Kamil Maternity and Children's Diseases Training and \\ Research Center, Istanbul, Turkey \\ 2Pediatric Endocrinology, University of Health Sciences, Istanbul Zeynep Kamil Maternity and Children's Diseases Training and Research \\ Center, Istanbul, Turkey
}

\begin{abstract}
According to additional anomalies, transverse testicular ectopia (TTE) is classified into three groups. Type-2 TTE, accompanied by persistent mullerian duct syndrome, constitutes approximately $20 \%$ of the patients. Surgical treatment should be planned after careful physical examination, ultrasonography, and genetic/endocrinologic evaluation. Herniorrhaphy, orchiopexy with testicular biopsy, and excision of the mullerian structures are the most appropriate surgical approaches in cases of TTE with persistent mullerian duct syndrome. We aimed to share our approach to the diagnosis and treatment of a patient with type-2 TTE. Possibility of TTE should be kept in mind in children with nonpalpable testis on one side and inguinal hernia on the other side.
\end{abstract}

Keywords: Child; male pseudohermaphroditism; orchiopexy; Persistent Mullerian Duct Syndrome; Testicular Ectopia.

Cite this article as: Cansaran S, Moralioglu S, Celayir A, Bosnali O, Yesiltepe Mutlu RG. Management of Transverse Testicular Ectopia with Persistent Mullerian Duct Syndrome. North Clin Istanb 2018;5(4):357-360.

$\mathrm{T}$ ransverse testicular ectopia (TTE) is a rare anomaly in boys in which both testes pass through the same inguinal canal, and it is usually accompanied by an inguinal hernia [1-5]. The majority of patients present with ipsilateral inguinal hernia and contralateral nonpalpable testis $[1-4,6-8]$. TTE is often accompanied by inguinal hernia, hydrocele, persistent mullerian duct syndrome (PMDS), disorders of sex development (DSD), and karyotype abnormalities $[6,7]$. PMDS is seen in approximately $20 \%$ of cases with TTE [2-6].

TTE is also called as crossed testicular ectopia, testicular pseudoduplication, unilateral double testis, and transverse aberrant testicular maldescent $[3,4]$. Ectopic testis lies in the opposite hemiscrotum, inguinal canal, or deep inguinal ring $[1,2,7]$.
PMDS may occur due to MIS (mullerian inhibiting substance) and MISR-II (mullerian inhibiting substance-type II receptor) gene mutations. It has autosomal recessive transmission $[1,4,6,8-10]$. Uterus, fallopian tubes, and upper two-third of vagina persist in a normal, virilized male. Karyotype is 46, XY [4-6, 8] Herein, we aimed to share our experience and discuss our surgical treatment method in a case with TTE and PMDS.

\section{CASE REPORT}

Two-month-old male patient was admitted to our pediatric surgery department due to antenatally diagnosed bilateral hydronephrosis. There was no history of uri-

Received: November 02, 2017 Accepted: January 22, 2018 Online: August 08, 2018

Correspondence: Dr. Sabri CANSARAN. Saglik Bilimleri Universitesi, Istanbul Zeynep Kamil Kadin ve Cocuk Hastaliklari Saglik Uygulama ve Arastirma Merkezi, Cocuk Cerrahisi Klinigi, Istanbul, Turkey.

Phone: +90 20163910680 - 2022 e-mail: sabrican@hotmail.com

(c) Copyright 2018 by Istanbul Provincial Directorate of Health - Available online at www.northclinist.com 
nary tract infection during postnatal follow-ups. Right inguinal hernia and left nonpalpable testis were determined by physical examination, and two testes were in the right inguinal region. One of them was closer to the entrance of scrotum. Our pre-diagnosis was TTE, and the patient was also evaluated by a pediatric endocrinologist.

Ultrasound examination showed grade 3 ectasia on right kidney, and grade 2 ectasia on left kidney in that period. Urethra was normal, and there was no vesicoureteral reflux in voiding cystourethrography. Kidneys had no abnormality, and drained normally in mercaptoacetyltriglycine scintigraphy. Right testicle $9.4 \times 7.1$ $\mathrm{mm}$ and left testicle $9.7 \times 7.7 \mathrm{~mm}$ were measured in size and ovoid, $24 \times 4.5 \mathrm{~mm}$ in size, suspicious uterine-like structure was present behind the bladder on scrotal and pelvic ultrasonography respectively.

Karyotype analysis of the patient was reported as 46, $\mathrm{XY}$. Anti-mullerian hormone $7.6 \mathrm{ng} / \mathrm{ml}$ (normal range $28-142 \mathrm{ng} / \mathrm{ml}$ ), dihydrotestosterone $32.8 \mathrm{pg} / \mathrm{ml}$ (normal range $250-990 \mathrm{pg} / \mathrm{ml})$, androstenedione $<0.3 \mathrm{ng} /$ $\mathrm{ml}$ (normal range $0.6-3.1 \mathrm{ng} / \mathrm{ml}$ ), and total testosterone $0.13 \mathrm{ng} / \mathrm{ml}$ (normal range $1.66-8.11 \mathrm{ng} / \mathrm{ml}$ ) were found in low levels. The patient was also diagnosed as PMDS. Surgical treatment was planned according to the decision of Gender Research Committee.

The patient was operated when he was ten months old. Ureteral catheter was inserted by cystoscopy through the opening of utriculus prostaticus (Figure 1). Right/left testes and their cord structures, and rudimentary structures of the mullerian ducts were seen during inguinal exploration via right groin incision (Figure 2). All patent mullerian structures were excised after the right inguinal hernia repair. Left testicle was brought down to the left hemiscrotum transseptally through the right inguinoscrotal canal. Then, the right testis was brought down to the right hemiscrotum via the right inguinoscrotal canal, and bilateral orchiopexy was completed. An illustrative picture of the operation is shown in Figure 3. Preoperative biopsies were taken from each testis. Testicular biopsies were reported as normal testicular tissue, while rudimentary structure was reported as uterus with inactive endometrium.

Early postoperative period was uneventful, and testes were in the scrotum bilaterally at 1 year of age. Scrotal ultrasonography showed homogeneous appearance of testes. Right $(7.3 \times 8.6 \times 12.7 \mathrm{~mm})$ and left $(7.6 \times 8.2 \times 15$ $\mathrm{mm})$ testes were reported in normal size.

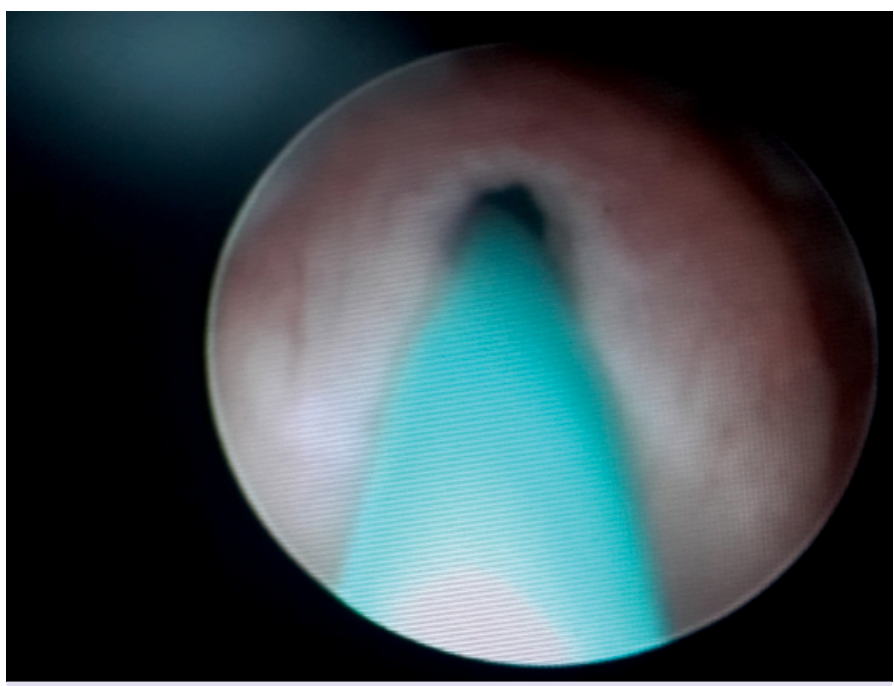

FIGURE 1. Ureteral catheter was inserted through an opening in utriculus.

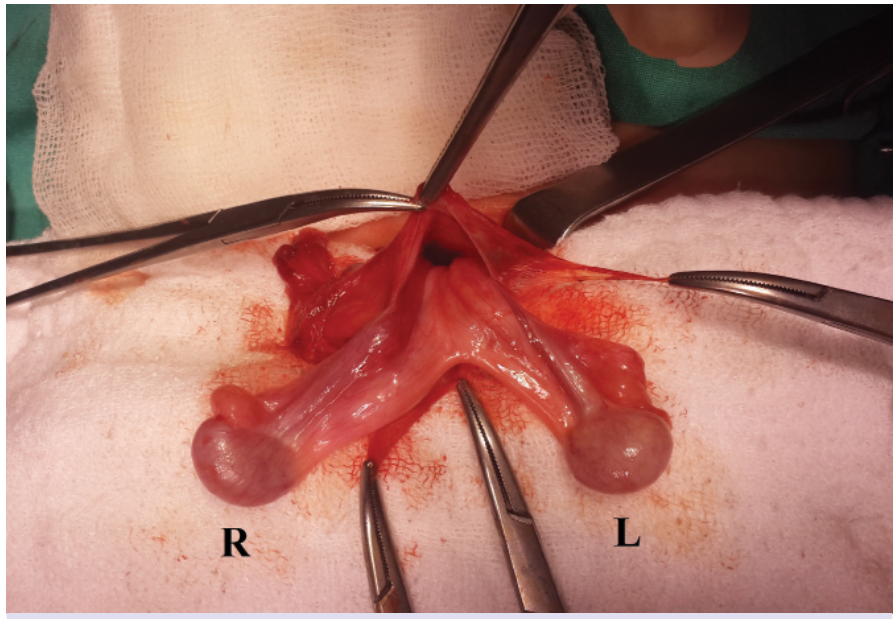

FIGURE 2. Both testes, epididymis, spermatic cords, vessels, and rudimentary structures were seen in right side inguinal exploration.
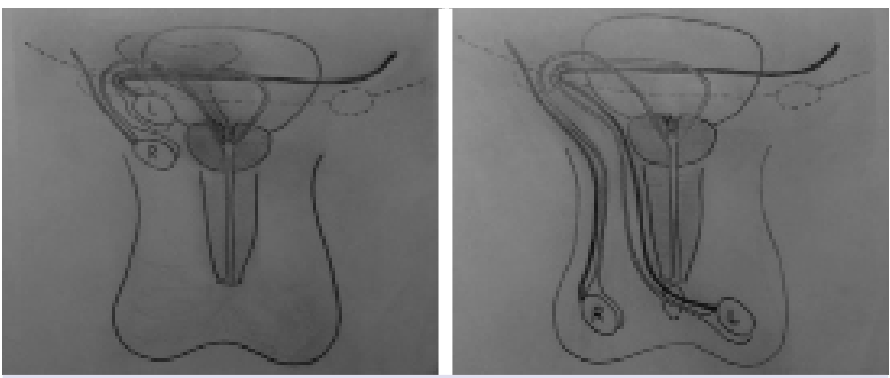

FIGURE 3. Illustration of the operation: Both testes, epididymis, spermatic cords, and vessels were passed from right inguinal canal to the right scrotum and transseptally to the left scrotum. All rudimentary structures were excised from right inguinal groin incision. 


\section{DISCUSSION}

There are many factors that are thought to play a role in the TTE etiology. Development of both testes from the same germinal ridge, early fusion of Wolffian ducts, testicular adherence to mullerian structures, and obstruction of the inguinal ring are suggested as causative in failure of testicular descent. The most widely accepted theory is abnormal attachment of gubernaculum which was proven by experimental studies $[3-5,7,10]$.

The TTE classification is made according to associated anomalies. Type I is only accompanied by inguinal hernia (40\%-50\%). Type II is accompanied by PMDS (20\%-30\%). Type III is accompanied by other anomalies such as DSD, hypospadias, scrotal abnormalities, seminal vesicle cysts, common deferent duct, and horseshoe kidney $[2,3,5-7]$. Based on this information, it can be said that our patient is type II TTE.

Because of the presentation with undescended testis or symptomatic inguinal hernia, TTE is detected during the surgery in many patients $[1,2,5,7]$. Sometimes, both testes may be palpated on the same side with ipsilateral inguinal hernia and contralateral unpalpable testis, as in our patient.

PMDS with TTE is a rare form of internal male pseudohermaphroditism that is caused by mullerian inhibiting factor (MIF) deficiency. Both testes are on the same side, and the mullerian duct remnants (fallopian tubes, uterus, upper part of vagina, etc.) are present in normally virilized XY patients. mullerian derivatives may be localized intraabdominally, as in our patient, or herniate from the inguinal canal [4-6].

PMDS can be sporadic, but most commonly, it occurs due to MIS and MISR-II gene mutation that has autosomal recessive transmission $[1,6,8,10]$. In our patient, there was no gene mutation in the genetic tests.

TTE is often accompanied by ipsilateral inguinal hernia and contralateral nonpalpable testicle. Both TTE and PMDS are usually detected incidentally during inguinal hernia or undescended testis operations. Preoperative diagnosis requires a high level of suspicion. If necessary, imaging methods should be used to support diagnosis $[1,3,5,7]$.

The optimal surgical approach in cases of TTE with PMDS should be protective for vas deferens, and include herniorrhaphy, orchiopexy, or orchiectomy (if the testicle cannot be brought down), excision of mullerian remnants and testicular biopsies $[1,3,4,6]$. Right and left or- chiopexies can be performed by passing through separate inguinal canals from separate groin incisions. Transseptal orchiopexy is easier because both testes have already passed through the same inguinal canal $[2,7]$; whereas in bilateral orchiopexy, there is also a risk of damaging the vessels of the ectopic testis with the additional contralateral incision. In our case, access to the posterior urethral region was easy following the high ligation of the right hernia sac through the right inguinal groin incision. Mullerian remnants and each ductus deferens were observed clearly. Both testes were easily brought down through the same inguinal canal, and spermatic cord length of the ectopic testis was sufficient to perform a transseptal orchiopexy.

The surgical management of PMDS remains controversial. Some authors refrain from recommending the removal of patent mullerian structures due to the risk of injury to vas deferens and the lack of the risk of developing malignancy $[5,10]$. However, recent studies have shown that remaining patent mullerian structures have a malignancy potential $[8,9]$. Orchiectomy (if necessary) or excision of mullerian remnants are deemed useful in preventing malignancies $[3,6,8,9]$. For reasons discussed above, all mullerian remnant structures were excised just proximal to the urethral connection using a gentle technique to protect the vas deferens before adulthood.

\section{Conclusion}

In cases of TTE with PMDS, the length of the cord and vessels of the ectopic testis is the major factor in deciding whether to bring down the testis ipsilaterally or contralaterally. If bringing down the ectopic testis is not possible due to short cord and vessels, excision may be considered due to risk of possible malignancy.

Informed Consent: Written informed consent was obtained from the patient for the publication of the case report and the accompanying images.

Conflict of Interest: No conflict of interest was declared by the authors.

Financial Disclosure: The authors declared that this study has received no financial support.

Authorship Contributions: Concept - S.C., S.M., A.C., O.B., R.Y.M.; Design - S.C., S.M., A.C., O.B., R.Y.M.; Supervision - S.C., S.M., A.C., O.B., R.Y.M.; Materials - S.C., S.M., A.C., O.B., R.Y.M.; Data collection \&/or processing - S.C., S.M., A.C., O.B., R.Y.M.; Analysis and/or interpretation - S.C., S.M., A.C., O.B., R.Y.M.; Writing S.C.; Critical review - S.M., A.C. 


\section{REFERENCES}

1. Patil V, Muktinaini S, Patil R, Verma A. Persistent müllerian duct syndrome: a case report. Indian J Surg 2013;75(Suppl 1):460-2. [CrossRef]

2. Akin M, Erginel B, Bilici S, Gedik S, Yıldız A, Karadağ CA, et al. Crossed testicular ectopia: Report of six cases. Afr J Paediatr Surg 2014;11:269-72. [CrossRef]

3. Karakuş SC, Kılınçaslan H, Ertaşkın I, Koku N, Deliağa H. Delayed and incidental diagnosis of transverse testicular ectopia. Balkan Med J 2012;29:447-9. [CrossRef]

4. Deepika, Kumar A. Persistent mullerian duct syndrome with transverse testicular ectopia: rare entity. J Clin Diagn Res 2014;8:162-3.

5. Alamsahebpour A, Blachman-Braun R, Gupta A, Castellan M, Campos S J, Gosalbez R. Laparoscopy and transseptal orchiopexy in the management of transverse testicular ectopia. Curr Urol Rep 2015;16:48.

6. Telli O, Gökçe MI, Haciyev P, Soygür T, Burgu B. Transverse testicular ectopia: a rare presentation with persistent Müllerian duct syndrome. J Clin Res Pediatr Endocrinol 2014;6:180-2. [CrossRef]

7. Farikullah J, Ehtisham S, Nappo S, Patel L, Hennayake S. Persistent Müllerian duct syndrome: lessons learned from managing a series of eight patients over a 10-year period and review of literature regarding malignant risk from the Müllerian remnants. BJU Int 2012;110:E1084-9. [CrossRef]

8. Wei CH, Wang NL, Ting WH, Du YC, Fu YW. Excision of Mullerian duct remnant for persistent Mullerian duct syndrome provides favorable short- and mid-term outcomes. J Pediatr Urol 2014;10:929-33.

9. Wuerstle M, Lesser T, Hurwitz R, Applebaum H, Lee SL. Persistent mullerian duct syndrome and transverse testicular ectopia: embryology, presentation, and management. J Pediatr Surg 2007;42:2116-9. [CrossRef]

10. Naouar S, Maazoun K, Sahnoun L, Jouini R, Ksia A, Elezzi O, et al. Transverse testicular ectopia: a three-case report and review of the literature. Urology 2008;71:1070-3. [CrossRef] 